\title{
Managing The Evolution Of A Revolution: Marketing Implications Of Internet Media Usage Among College Students
}

Connie Browning Budden, Southeastern Louisiana University Janet Foster Anthony, Southeastern Louisiana University

Michael C. Budden, (E-mail: mbudden@selu.edu), Southeastern Louisiana University Michael A. Jones, (E-mail: mijones@selu.edu), Southeastern Louisiana University

\begin{abstract}
It is no surprise that internet usage among college students has seen a marked increase in recent years. The increasing usage of this medium portends direct, negative impacts relative to the use of other media by this important market segment. Marketers are interested in internet usage information in order to determine the best methods for tapping into this potential market. Research focused on internet usage patterns of college students was conducted. Usage patterns by student classification and gender were studied. Specific use of the Facebook, MySpace and YouTube websites were investigated.
\end{abstract}

\section{INTRODUCTION}

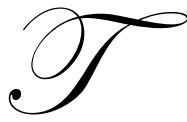

he internet was initially developed and its use restricted to scientific research by the US Department of Defense (Cheung \& Huang, 2005). Since its widespread adoption, the internet has impacted the lives of people from all walks of life, including impacts on business, shopping and social activities (Cheung \& Huang, 2005). Internet social activities have presented marketers with challenges as well as opportunities to reach specific target markets.

Facebook, introduced two years ago was originally a networking site limited to college students. The site was opened to high school students last September and will soon be available to anyone with a valid e-mail address (Kornblum, 2006). Facebook currently serves over 7.5 million registered users and is seventh among the more accessed sites in the U.S. (Cuesta, 2006). Facebook and the other major social site, MySpace, are two of the most popular social sites for today's college students (Cuesta, 2006). MySpace's membership has more than 40 million members as of the end of 2005 (Hempel \& Lehman, 2005).

YouTube is the newcomer to the college social scene created in 2004 (Keen, 2006). It allows the posting and viewing of videos by individuals, organizations and businesses. While new and small compared to MySpace and Facebook, its two creators recently sold it for $\$ 1.6$ billion to Google. It is reported that YouTube viewers watch more than 100 million videos each day(Gill, 2006).

Internet usage is increasing rapidly among the general population but even greater among college students. Internet usage among U.S. adults has risen and is reportedly at $56 \%$ for predominantly white, well-educated and affluent individuals (Odell, Korgen, Schumacher \& Delucchi, 2000). Odell et al (2000) found no significant difference in internet usage between men and women. Among college students, $79 \%$ indicated that the internet has had a positive impact on their college careers (Halligran, 2005). Further, 86\% of college students indicated they have gone online as compared to $50 \%$ of the general population. Research indicates some differences in the purposes of internet usage between the genders. Females tended to use the internet for E-mail and school research while males had higher usage of sex sites, research, purchases, news, games and music (Odell, Korgen, Schumacher \& Delucchi, 2000). 
A study conducted by the Harris Poll for Northwestern Mutual indicates that the college class of 2001 has a $100 \%$ usage of the internet (Futurist, 2001). Usage among this group has nearly doubled from 6 hours a week on first entering college to 11 hours a week currently (Futurist, 2001). In the current study, students were found to spend 9.6 hours per week on the internet which is not too different from the Northwestern Mutual findings.

Surprisingly, three-fourths of students in one study felt that usage of the internet brought them closer to people (Weiskirich \& Murphy, 2004). Weiskirich \& Murphy (2004) found that the socializing potential of the internet is increasing with the expanding of connectivity and interactivity by students. Internet usage for students at public universities was significantly higher than that of students attending private universities (Davis, Smith, Rodrigue, Pulvers, 1999). Davis et al found that men at public universities spent more time on the internet than their counterparts at private universities.

Internet usage for college students has increased but social networking online has been growing at an accelerating pace. This increasing use of the internet for socialization has major implications for marketers and other social scientists. The potential negative impact on the bottom line of marketers relying on the use of historical media to reach technically-astute markets may be significant.

A variety of marketers have tried to create their own online networks. Some have been more successful that others though most have had little luck creating these online networks - the rule being that users - not providers drive the success or failure of social networks. According to (Hempel \& Lehman, 2005), among the more successful commercial marketers were Apple, Disney, Coca-Cola, and Target. Apple was asked to sponsor an "Apple-lovers" group online. Students participate in contests and discount programs through the Apple-lovers site. In addition, Walt Disney set up online blogs to promote "The Hitchhiker's Guide to the Galaxy." The site received about 5,000 subscribers and 220,000 page views. Target stores sponsored a video of Shaun White snowboarding and skateboarding. Over 31,000 viewers joined allowing them to watch videos and shop the store. Coca-cola sponsored a Sprite profile on MySpace and a spot on Buzz-Oven. Over 22,875 people linked to the Sprite site. The importance of reaching and catering to the college market becomes apparent when you consider college students have an estimated \$200 billion spending budget (Hempel \& Lehman, 2005).

\section{RESEARCH}

The main objective of this project was to investigate usage patterns and market usage of the internet as a communication medium among college students. To further understand the internet phenomenon among college students specific research objectives included the following:

1. To investigate the level of use of Facebook.com by college students

2. To investigate the level of use of MySpace.com by college students

3. To investigate the level of use of YouTube.com by college students

4. To investigate the level of use of television viewer-ship by college students

5. To investigate the level of use of radio listener-ship by college students

\section{RESEARCH METHODOLOGY}

A media diary (journal) was developed to compile internet and media usage information. Each diary included questions detailing demographic information about the respondents. The diary was pretested first on a group of five students. This pretest resulted in minor changes to the diary including changes in the size of the columns and the hour of the day at which the diary would start (the starting time each day was changed from 8:00 a.m. to 6:00 a.m. based on comments from this initial group to test the diary. A second pretest using a group of 40 students was conducted using a questionnaire which included demographic questions and a question regarding the recall of advertising on the individual sites. The second pretest was given to a class of 40 undergraduate students and no changes were made to the diary or questionnaire based on that pretest as there appeared to be no further changes necessary. 
The diary was distributed to 350 undergraduate and graduate students across different departments at a statesupported public university. A response rate of $77 \%$ was obtained as 272 usable diaries were returned. The respondents were primarily undergraduate students (86\%) while the remaining $14 \%$ were graduate students. Males made up $41 \%$ of the respondents while females made up 58\%. This is not too unlike the gender breakdown for the University, where $63 \%$ are female and $47 \%$ male. Freshman and sophomores constituted $37 \%$ of the respondents while juniors and seniors constituted $48 \%$ of respondents.

Students were asked to use the diaries to track their media usage during a week in the fall 2006 semester. The diaries allowed students to enter the amount of time they spent each day using the internet in general (other than the three websites of interest), the time spent using each of the three specific websites of interest, radio and television. General internet usage included using email, surfing the web, research and learning activities including time on BlackBoard for internet-based classes, and other activities not associate with the three sites of interest.

The students were given directions on completing the diary on the day they were distributed. In addition, they were reminded every other day for a week to complete the diary on a regular basis throughout each day. This was to encourage accurate reporting of data on a timely basis. While some reminders were given in class, others were emailed to the students. Each student received at least three reminders during the week the study was conducted.

On the last day of the study, students were sent an email and/or were encouraged in class to return the completed diaries on the next day. Along with the diaries, the completed demographic and media recall sheets were returned to the researchers. The total minutes each respondent spent using the media each day and all other data collected were input into an Excel spreadsheet that provided the basis for the SPSS data analysis. Frequencies and cross-tabs along with Chi-Square Goodness of Fit were calculated for the variables of interest.

\section{MEASURES}

Participants in the study supplied demographic and other descriptive information along with their diaries. The data provided the following information: gender, age, race, classification and major. In addition, information was gathered on the number of advertisements noticed by participants on MySpace, Facebook and YouTube. Participants were asked to list any advertisements they remembered seeing while visiting any of the three sites under study. Finally, information on purchases made over the internet was obtained to provide an assessment of the internet shopping experience of the students.

\section{RESULTS}

Students were found to spend large amounts of time using the different media. The Internet category included spending time using e-mail and Blackboard, conducting research and other uses, excluding time spent on MySpace, Facebook and YouTube Utilization of these three specific sites were recorded separately. Although all internet media usage appears to be heavy by students (approximately 10 hours per week on a weighted average basis), students reported spending significant time listening to the radio and watching television. Indeed, some mentioned that they often listened to the radio or watched television while using the internet. So while internet usage may be increasing, students are still using historical media to a large extent.

Table 1: Average Number Of Hours Spent On Media In One Week

\begin{tabular}{|c|c|c|c|c|c|}
\hline $\begin{array}{c}\text { MySpace } \\
(\mathrm{n}=153)\end{array}$ & $\begin{array}{c}\text { Facebook } \\
(\mathrm{n}=153)\end{array}$ & $\begin{array}{c}\text { YouTube } \\
(\mathrm{n}=34)\end{array}$ & $\begin{array}{c}\text { Other Internet } \\
(\mathrm{n}=233)\end{array}$ & $\begin{array}{c}\text { Radio } \\
(\mathrm{n}=202)\end{array}$ & $\begin{array}{c}\text { Television } \\
(\mathrm{n}=250)\end{array}$ \\
\hline 3.72 & 2.50 & 2.15 & 6.83 & 8.79 & 13.49 \\
\hline
\end{tabular}

As can be seen in Table 1, of the 272 students responding, 250 reported spending more than 13 hours per week watching television. This is significant, as 202 also reported spending more than 8 hours per week listening to radio. At the same time, the average student in the study spent almost 10 hours per week accessing the internet. 
Analysis of the data for differences in media usage between the two genders was completed using the ChiSquare measure of independence. Differences were found between genders relative to the usage of the three sites MySpace, Facebook and YouTube. Although not significantly different, females spent more time on MySpace and Facebook than their male counterparts. Males spent statistically significantly more time on YouTube than female participants. The difference between male and female use of YouTube was found to be statistically significant at better than the .01 level. Also, surprisingly perhaps, females spent more time on non-internet media (radio and television), than their male counterparts.

As can be seen in Table 2, males accessed YouTube with a better than 4 to 1 ratio, relative to females - the largest gap between the genders. On the other hand, the great majority of males and females reported spending time watching television. The proportion of females listening to radio was also found to be greater than the proportion of males listening to radio.

Table 2: Observed Media Usage And Gender Of Participants

\begin{tabular}{|c|c|c|c|c|c|c|}
\hline Gender/Media & MySpace & Facebook & YouTube & Internet & Radio & TV \\
\hline Male & 62 & 56 & 28 & 90 & 76 & 103 \\
\hline Female & 91 & 97 & 6 & 143 & 126 & 147 \\
\hline Total & 153 & 153 & 34 & 233 & 202 & 250 \\
\hline
\end{tabular}

Table 3: Expected Media Usage And Gender Of Participants

\begin{tabular}{|c|c|c|c|c|c|c|}
\hline Gender/Media & MySpace & Facebook & YouTube & Internet & Radio & TV \\
\hline Male & 61.95 & 61.95 & 13.77 & 94.34 & 81.79 & 101.22 \\
\hline Female & 91.05 & 91.05 & 20.23 & 138.66 & 120.21 & 148.78 \\
\hline
\end{tabular}

Chi-Square 26.76617, $\mathrm{df}=5$

$\mathrm{p}$-value $=.01$

Table 4: Computed Chi-Square Statistics

\begin{tabular}{|c|c|c|c|c|c|c|}
\hline Gender/Media & MySpace & Facebook & YouTube & Internet & Radio & TV \\
\hline Chi-Square & 67.822 & 52.500 & $33.130^{*}$ & 132.029 & 106.456 & 103.195 \\
\hline Df & 75 & 55 & 20 & 115 & 114 & 105 \\
\hline
\end{tabular}

$*$ p-value $=.01$

Analysis of media usage based on student classification indicated that there were not significant differences in media usage patterns of lower classmen (Freshmen \& Sophomores), upper classmen (Juniors \& Seniors), and graduate students. Differences in media usage were found in MySpace, Facebook, YouTude, General Internet, Radio and Television, although these differences were not statistically significant. Upper level students were found to use the internet, and especially YouTube, more than their lower level undergraduate counterparts and graduate students. Upper classmen also spent more time listening to the radio and watching television than did other students.

Marketers wishing to reach upper classmen would be well-advised to use traditional media. In addition, marketers targeting upper classmen, especially male upperclassmen, may find YouTube to be a viable communication outlet as they tend to use YouTube to a greater extent than younger students. 
Table 5: Observed Media Usage And Classification Of Participants

\begin{tabular}{|l|c|c|c|c|c|c|}
\hline Classification/Media & MySpace & Facebook & YouTube & Internet & Radio & TV \\
\hline Lower Classmen (F\&S) & 69 & 66 & 13 & 74 & 73 & 90 \\
\hline Upper Classmen (J\&Sr) & 68 & 67 & 16 & 122 & 100 & 124 \\
\hline Graduate Students & 16 & 20 & 5 & 37 & 29 & 36 \\
\hline Total & 153 & 153 & 34 & 233 & 202 & 250 \\
\hline
\end{tabular}

** $\mathrm{F}=$ Freshman, $\mathrm{S}=$ Sophomore, $\mathrm{J}=$ Junior \& Sr = Senior

Table 6: Estimated Media Usage And Classification Of Participants (Minutes)

\begin{tabular}{|l|c|c|c|c|c|c|}
\hline Classification/Media & MySpace & Facebook & YouTube & Internet & Radio & TV \\
\hline Lower Class & 57.47 & 57.47 & 12.77 & 87.52 & 75.87 & 93.90 \\
\hline Upper Class & 74.19 & 74.19 & 16.49 & 112.98 & 97.95 & 121.22 \\
\hline Graduate & 21.35 & 21.35 & 4.74 & 32.51 & 28.18 & 34.88 \\
\hline
\end{tabular}

Chi-Square 10.11565, $\mathrm{df}=10$

(not significant)

Table 7: Computed Chi-Square Statistics

\begin{tabular}{|l|c|c|c|c|c|c|}
\hline Classification/Media & MySpace & Facebook & YouTube & Internet & Radio & TV \\
\hline Chi-Square & 154.047 & 126.872 & 44.734 & 254.668 & 233.325 & 223.192 \\
\hline Df & 150 & 110 & 40 & 230 & 228 & 210 \\
\hline
\end{tabular}

\section{DISCUSSION}

This study supports previous research which indicates time spent using the internet for a variety of purposes is similar for males and females. However, while they may spend similar amounts of time on the internet, their usage patterns differ, especially in regards to YouTube. More females than males use Facebook and MySpace while males make significantly more use of YouTube than females. Surprisingly, students are still spending significant time with television and radio. Indeed, the use of historical media still exceeds that of internet media by a large degree.

Media usage patterns by participants of the study based on student classification indicated very little difference among the different media. Upper level classmen spent more time on YouTube than lower level classmen and graduate students. Upper classmen also spent more time on the internet, listening to the radio and watching TV.

The major challenge with the study was insuring that students completed the Media Diary everyday and kept it current throughout the day. To address this concern, researchers allowed in-class time to complete the diary on class days. Students were e-mailed multiple times during the week reminding them to complete their diary in a regular, timely manner. In addition, announcements were made in the classroom encouraging students to keep their diaries current.

\section{LIMITATIONS}

The main limitation of the study was that the sample was a convenience sample rather than a scientifically chosen random (probability) sample. Also, the fact that the study was conducted at only one university during one week of the fall term precludes an applicable, universal rule. The study confirms or parallels findings by other researchers and indicates the importance and relevance of this research. Media usage patterns of college students are changing. Understanding these changes is a step to improved target marketing. 


\section{MARKETING STRATEGY IMPLICATIONS}

The findings of this research provide marketers guidance in strategic decisions regarding marketing to college students. Effectively reaching markets through targeted appeals requires informed decisions on media selection. By understanding college student media habits and their evolution marketers may make the best decisions given the realities of resource constraints. Marketers wishing to reach college students may still utilize traditional media that appeals to the market. College students are still spending significant time listening to radio and watching television. The historical advantages offered by these two media still hold though the internet has gained a significant foothold.

Marketers need to heed changes in media usage patterns by this economically important market. Females in particular are increasingly spending time using MySpace and Facebook. The use of those two sites as social interaction vehicles continue to grow. Savvy marketers may use these two heavily-trafficked internet sites to reach college females.

Marketers wishing to reach male college students have another outlet that offers promise as a potential advertising vehicle. YouTube is heavily-trafficked by a broad spectrum of users including, according to this study, college males. While college males also make use of MySpace and Facebook, YouTube is used by more males than females.

Upper-classmen also reported a higher usage rate of YouTube than other students. Marketers wishing to target upper-classmen may wish to utilize YouTube as well as traditional media since they reported significant use of these outlets.

\section{SUMMARY}

With the huge impact of internet usage among college students in recent years, marketers have reached an era where traditional means of advertising have shifted to the World Wide Web. Many marketing managers are left puzzled; wondering where are America's youth? Simply stated, more young adults are accessing the internet as a convenient tool to accomplish a wide array of interests, such as, socializing, entertainment, taking online classes and research. These young adults, accompanied with their $\$ 200$ billion spending budget, are "clicking" their way into being one of the hottest target markets in the new millennium. Since the traditional means of media outreach has taken a heavy hit, marketing firms will need to find creative ways using the internet to tap into the huge number of internet users. In order for savvy marketers to successfully reach this potential market, they must learn how to reach “Generation @” through social networks. Social networks, including Facebook, MySpace, and YouTube are among the hottest sites to reach this potential market and offer promise to marketers desiring to reach that market.

\section{REFERENCES}

1. Cheung, W., Huang, W. (2005). Proposing a framework to assess internet usage in university education: an empirical investigation from a student's perspective. British Journal of Educational Technology, 36(2), 237-253.

2. Cuesta, C. (2006). Students love social-networking sites-and so do employers. http://www.Foxnews.com/story/0,2933,208175,00.html.

3. Davis, S., Smith, B., Rodigue, K., Pulvers, K. (1999). An examinination of internet usage on two college campuses. College Student Journal, 33(2), 257-261.

4. Gill, J., (2006). Contagious commercials. Inc., 28(11), 31-32.

5. Halligan, T. (2003). It's an internet world out there. University Business, 11.

6. Hempel, J., Lehman, P. (2005). The MySpace generation. Business Week, 3963, 88-93.

7. Keen, J. (2006). Websites with candidates' praise. USA Today, 3.

8. Kornblum, J. (2006). Facebook will soon be available to everyone. USA Today, 9-11.

9. Levy, S., (2006). Brightcove: a safe harbor? Newsweek, 148(20), e6-e7.

10. Odell, P., Korgan, K., Schumachere, P., Delucchi, M. (2000). Internet use among female and male college students. Cyber Psychology \& Behavior, 3(5), 855-862.

11. The Futurist (2001, September-October). The web-connected generation: 9.

12. Weisskirch, R., Murphy, L. (2004). Friends, porn, and punk: sensation seeking in personal relationships, internet activities, and music preference among college students. Adolescence, 39(154), 189-201. 